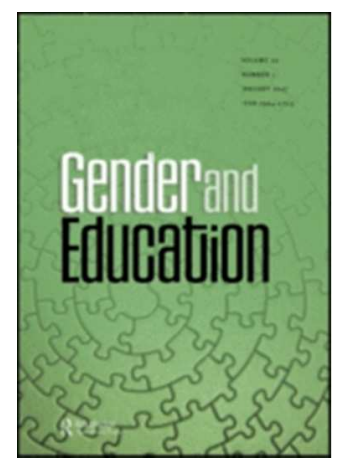

\title{
Teachers negotiating discourses of gender (in)equality: the case of equal opportunities reform in Andalusia
}

\begin{tabular}{|r|l|}
\hline Journal: & Gender and Education \\
\hline Manuscript ID: & CGEE-2014-0038.R4 \\
\hline Manuscript Type: & Original Paper \\
\hline Keywords: & $\begin{array}{l}\text { Equality < SUBSTANTIVE TOPICS, Gender Mainstreaming < SUBSTANTIVE } \\
\text { TOPICS, Discourse analysis < METHODS AND METHODOLOGY, Education } \\
\text { Policy < SUBSTANTIVE TOPICS }\end{array}$ \\
\hline \multicolumn{2}{|l}{} \\
\hline
\end{tabular}

\section{SCHOLARONE ${ }^{m}$}

Manuscripts 
Teachers negotiating discourses of gender (in) equality: the case of equal opportunities reform in Andalusia

Mercedes Cubero ${ }^{1}$, Andrés Santamaría 1 , Ma Ángeles Rebollo² ${ }^{2}$ Rosario Cubero ${ }^{3}$, Rafael García² \& Luisa Vega ${ }^{2}$

1 Laboratory of Human Activity, Department of Experimental Psychology, Faculty of Psychology. University of Seville, Spain

2 Department of Methods of Research and Educational Assessment, Faculty of Educational Sciences, University of Seville, Spain

3 Laboratory of Human Activity, Department of Developmental Psychology and Education, Faculty of Psychology, University of Seville, Spain

CORRESPONDING AUTHOR: Dr. Andrés Santamaría, Department of Experimental Psychology, University of Seville. Camilo José Cela, s/n 41017, Seville, Spain. email: asantamaria@us.es 
This article examines how school teachers who were responsible for coordinating and implementing the First Plan for Equal Opportunities between men and women in Education in Andalusia, discussed and gave meaning to their experiences and the potential changes generated by this reform. We argue that it is important to find out how teachers, who are responsible for implementing the Gender Equality Plan, construct, negotiate and validate their actions in this changing process, and we attempt to do so through examining their discourse on gender equality. The focus is on teachers' actions and the cultural tools (discursive and semiotic resources) they employed during their interactions with other teachers, and how this helped them to construct meanings and values related to gender equality. In other words, we try to show how gender culture was constructed through conflicts experienced by teachers in the application of the First Andalusian Equality Plan in Education. Through analyzing conflict in conversation, we identify the arguments used by teachers to negotiate and interpret the application of the equality plan. We argue that this close analysis assists in understanding and evaluating the impact of the educational equality plan.

We will start by contextualizing the First Plan for Equality in Education in Andalusia. In this section, we will address the current relevance of this particular topic in Spain, specifically in Andalusia, presenting the main principles and objectives of this plan. We will examine some theoretical issues about doing (gender) equality in education, noting that our study draws on the theoretical approach of 'doing gender' as elaborated by authors such as Butler, (1990, 1993), Crawford (2006) Garfinkel (1967) Kitzinger (2009), and West and Zimmerman (1987). We adopt a perspective based on the arguments of these authors in order to study the processes used to construct and validate shared meanings about gender equality and inequality in a 
school setting. To do so, we developed a methodological approach to analyze discursive practices that create, as we shall show, shared meanings and produce changes in school culture about gender equality. The methodology is based on an understanding of interactive processes as sites for the joint construction and negotiation of meanings, and on discourse as a social mode of thinking. We shall discuss these notions in the following section. This approach framed our study of how notions of gender equality were constructed through teachers' discussions about coeducation.

\section{Contextualizing the First Plan for Equality in Education in Andalusia}

During the late twentieth century and the beginning of the twenty-first, the consolidation of democracy in Spain implied the adoption of equality as a principle and objective of state policy (Cuenca, 2008). It was an important and significant milestone in the social and legal development of Spanish society. As a result, a number of laws were specially developed to promote equality between women and men (Lombardo 2005). Andalusia, with a long history of socialist government, is one of the most active regions of Spain in implementing the principle of equality in public policies. In 2005, the regional government of Andalusia introduced the First Plan for Equal Opportunities between Men and Women in Education, the goal of which was to promote a new gender culture in schools. This was a response to well-documented gender inequalities in co-educational school settings: there are no state schools with sex-segregated education in Andalusia.

The I Plan for Equal Opportunities between Men and Women in Education (Junta de Andalucía, 2005) proposes a set of specific goals such as: 
Objective 1: To provide a better understanding of the differences between boys and girls, men and women, not in terms of biological differences but in terms of diverse educational patterns. Such patterns give meaning to men and women's interactions. Understanding them should prevent and correct the discrimination that such differences produce. This should also promote relationships based on the freedom of choice of all citizens (men and women).

Objective 2: To promote school conditions that foster educational practices to help challenge the stereotypes associated with domination and dependence.

Objective 3: To promote change in gender relations by encouraging greater personal autonomy among students.

Objective 4: To correct the imbalance between male and female teachers in school activities and responsibilities in order to provide children and teenagers with different performance models.

In this Plan, teachers, especially those responsible for coordinating and implementing the Gender Equality Plan, are considered to be a key element in changing the gender culture. So, the state has proposed what has been called teacher experts in co-education, according to their background and their experience in previous educational innovations, to explicitly develop equality in schools. The term co-education, is understood to describe pedagogical approaches that are able to respond to feminist claims on equality, and which propose a reconstruction of the settings for teaching and learning according to gender perspectives (Institute for Women, 2008). The background and professional experience necessary for a teacher to be considered expert in co-education includes participation in curriculum projects for school innovation and change in equality of gender and gender culture (elaboration of projects and school activities for gender equality, studies related to 
visualization of in-equality in schools, publications, and participation in conferences, etc.). There is one teacher expert on co-education responsible for each school or school area. The responsibilities of those teachers are to create and propose specific activities to perform inside the classrooms; evaluate and correct the language used in classrooms and also in the official documents elaborated by the schools; develop groups for training teachers; assess the effectiveness of each school promoting all changes towards gender equality (through interviews, participant observation or tests); and so on.

Understanding the views and practices of the policy makers in designing the Plan for Equality is important for examining the implementation of the plan. Further, the nature of relationships between policy makers and their colleagues in schools is also crucial for understanding the construction of a gender culture in schools based on realizing equality.

Our analysis of the equality plans and policies is framed by a 'doing gender' approach (Crawford, 2006; Kitzinger, 2009; Liss et al., 2001; West and Zimmerman, 1987), which provides a theoretical model for examining how gender is "done" in educational contexts. It takes a multi-level perspective that integrates the individual, interactive (face-to-face interactions) and socio-cultural planes (Rader and Cossman, 2011). The 'doing gender' approach also provides an opportunity to study processes of educational change related to the construction of social meanings, and to analyze potentially new discursive practices about gender equality.

\section{Examining doing (gender) equality in education: some theoretical issues}

The importance of "doing gender" as a conceptual contribution to social thought has been widely discussed, revised and updated (Martin, 2003; 
Messerschmidt, 2009; Ridgeway, 2009; West and Zimmerman, 1987, 2009). We take this standpoint to examine the processes used by teachers in this study to construct and validate shared meanings about gender equality and inequality, and to understand how gender is done in educational settings in terms of teachers' discursive and semiotic resources.

From this theoretical perspective, various "doing gender approaches" have challenged accepted views of gender as either an individual role or as a reflection of natural differences rooted in biology (Butler, 1990, 1993; Garfinkel, 1967; West and Zimmerman, 1987, for example). West and Zimmerman (1987, 2009,) among others, drew attention to the ways in which gender differences are "doing" in social interactions and contexts. They argued that gender is not an attribute of individuals but a system of meanings, a way of making sense of actions which are oriented to creating and maintaining a certain gender social order (West and Zimmerman 1987, 2009). Gender is understood as a system of meanings that organizes interactions, giving them sense and direction. Gender is something that people do (Crawford, 2006; Crawford and Chaffin, 1997). This theoretical approach has given rise to numerous studies which have further developed this complex conception of gender, suggesting that gender is a multilevel social system in which institutional, interactive and individual levels are interrelated (Crawford and Chaffin 1997; Marshall, 1999). Messerschmidt (2009) has examined gender interactions in three distinct social contexts: the family, the school, and the peer group. On the one hand, Messerschmidt's data shows that young people do not possess gender; instead gender is something they do in interaction with others. Young people accomplish gender through social interactions, and so their specific type of gender construction articulates with particular social situations. On the other, youth practices are evaluated 
by co-present participants in relation to normative conceptions of gender within each setting $(2009$, p. 87). In short, the idea of "doing gender" provides us with a powerful tool for analyzing gendered behavior and interactions in different social settings and practices.

From this view, Crawford (2006) considers gender as a social system that functions on three levels: (a) On the socio-cultural level, gender governs access to resources and power, regulating social positions and relationship models between men and women; (b) On the interactive level, gender is a dynamic process of representation of what it means to be a man or woman, built in daily, face-to-face interactions; (c) On the individual level, gender is expressed as an aspect of personal identity (expectations, interests, desires, etc.).

The socio-cultural level of gender systems in school contexts involves taking as objects of study the distribution and use of spaces in the school, the allocation of academic posts, and representation, syllabus content and materials, etc. The interactive level involves the study of interactions among staff, between staff and students, among students, between staff and parents, and so forth, in terms of questions of leadership, transmission of stereotypes and relationship models (cooperation, conflict, and violence). On the individual level, this perspective directs us towards studying academic performance, academic preferences and choices, aspirations, for example, according to gender.

We consider the First Plan for Equality between Men and Women in Education in Andalusia as a specific action or intervention at an institutional level aimed at promoting equality between men and women through education. In fact, the aim is, amongst others, to encourage educational practices of equality and to introduce changes in gender relations, and is therefore a good strategy for change at 
the socio-cultural level. This Plan introduced a series of changes in the three aforementioned levels in terms of school culture, which affected different dimensions such as syllabus, language, organization, and spaces. Laws are potent tools for social transformation because they create a new scenario for coexistence and an opportunity for the exercise of citizenship. However, we are well aware that the approval of a law is not going to bring about an immediate change to school reality, in terms of organization, and its set of values, traditions, and customs. The actions of the educational community (such as teachers, students, administrators, and family), or interventions in what we have referred to as the interactive and individual levels, are crucial for constructing new values, customs and practices.

Gaining an insight into interventions on the interpersonal level is directly related to the objective of this paper. As we have argued, it is important to find out how teachers, who are responsible of the implementation of the Gender Equality Plan, construct, negotiate and validate their actions in this changing process, and we attempt to do so through examining their discourse on gender equality. This perspective is connected to a specific way of understanding interactive processes, and to a specific way of understanding discourse, as we will now discuss.

\section{A conception of language and discourse for analyzing doing gender equality}

Discourse is not a channel for conveying messages but rather an activity which generates meaning. Discourse in general, and educational discourse in particular, is not simply a representation of thought in language; it should be regarded as a social mode of thinking. In accordance with this perspective, we agree with Kitzinger (2009), Mercer (2000), and Wertsch (1991), amongst others, on the importance of the semiotic dimension of the classroom and the consideration of this space as a setting 
for the joint construction and negotiation of meanings. For joint activity to be possible, the participants engaged in the interaction must be able to share perspectives; this mutual understanding has been defined as inter-subjectivity (Rommetveit, 1979). We understand each other insofar as we can share a common point of view, or when by interacting with each other we can reach a common reference, modifying our own position where necessary to bring about a greater harmony with that of others.

This approach analyzes inter-subjectivity as the actual process of creating meanings in discourse. In a previous study, Cubero and Ignacio (2011) revealed as the creation and maintenance of inter-subjectivity is closely related to how knowledge is validated in specific contexts; that is, how facts regarded as truths are constructed, which discursive resources are used to legitimize a specific version of the world and how the relevant sources of knowledge are established in a given context. In specific classroom settings in previous studies, we identified a series of discursive devices and mechanisms that bear relation, not only to the validation procedure followed during classroom activities, but also to the resources of validation or the provenance of the authority through which knowledge is legitimized. The validation process refers to the forms of reasoning and the justification of knowledge as "true" in classroom discourse, to how the participants in the classroom create and negotiate what is going to be considered the correct knowledge for the classroom, the contents to be learned and agreed. So the legitimized versions of facts through different sources in the classroom are expected to become shared knowledge for the classroom community. An example of one of the resources used to validate some facts or explanations is "Invocation". Invocations are described as semiotic resources used to validate specific points of view. In this paper we describe the invocations employed by teachers to 
validate their knowledge about questions related to gender inequality. Specifically, we analyze invocations in those situations in which there is no minimum level of shared meanings, generating a conflict related to the culture of gender at school.

On a more general plane of discourse, Mercer (2000) proposes and applies the notion of "discursive strategy" in relation to different forms of language use during these kinds of processes of negotiation and construction of shared meanings. Mercer (2000, p. 103) refers to discursive strategies as the specific ways or techniques of conversation used by teachers when they try to guide students' knowledge construction. Discursive strategies are intentional forms of conversation oriented towards a goal and which show the rules and obligations governing institutional settings. In this study, we also analyze the "discursive strategies for doing gender" which are directly related to the goals of feminism. A range of different scholarship (for example, Crawford, 2006; Kabeer, 2005; Liss et al. 2001; Reid and Purcell, 2004) has shown that the gender consciousness promoted by women's movements has some shared features such as: a) a sense of interdependence and shared fate with other women; (b) recognition of women's relatively low status and power compared to men; (c) attribution of power differentials to illegitimate sources, such as institutionalized sexism, and (d) an orientation towards collective action to improve women's position in society. Some of these features could be identified in our discursive strategy proposals used by teachers to create new shared meanings about gender equality in school. We present some data on this below.

According to the theoretical background presented above, we drew up the following study objectives: (1) To analyze how expert teachers in co-education construct meanings about gender (in) equality; (2) To identify their Discursive Strategies; and (3) To study Invocations in discourse. 


\section{A study of how gender equality is constructed through expert teachers' discourses on co-education: Methodological decisions}

Our aim here is show how gender culture is constructed through conflicts experienced by teachers in the application of a new regulation such as the First Andalusian Equality Plan in Education. Conflict in conversation becomes a space for negotiation and construction of shared meanings through the meeting between different voices or points of view. We need to identify the arguments used by teachers to negotiate and interpret the application of the equality plan, or, in other words, to create a certain level of inter-subjectivity about the meaning of materials, procedures and actions. This is essential for monitoring and evaluating the impact of educational equality policies and plans.

The study is located within a qualitative paradigm, based technically on the analysis of discourses 'uttered' by group discussants, including teachers responsible for gender equality. These group discussions take the form of debates between experts in equality and gender culture in schools. The exchanges in the group discussions allow us to analyse processes of negotiation and resolution of contradictions and conflicts. These are particularly useful for analyzing how opinions, attitudes, and orientations emerge, constitute, influence, and modify each other in an exchange of views (Bohnsack, 2004). Amongst other methodological advantages, participants in group discussions can determine their own topics of debates, and when and how they want to talk about them. However, it requires a certain degree of standardization, at least with respect to the opening questions. Group discussions are widely used in gender research. The application of group discussions in gender studies makes it possible for groups of people who are faced with the same set of issues to become 
more aware of the political and social process of construction of their experiences and potentially lead them to organize themselves towards change (Danielsson, 2012). In gender studies, group discussions have been shown to be very effective in observing how opinions are constructed and expressed, and how these are negotiated and modified through discussion (Kitzinger, 2009). Some advantages of this technique are: (a) It allows us to analyse how opinions are created and re-created in social interactions; (b) It generates more natural situations because they resemble everyday processes of social construction of meaning in interaction; (c) It reduces the power of interviewers because control of the content and interaction lies in the hands of the participants (Bohnsak, 2004).

For our purposes, the use of group discussions makes it possible to understand the ways in which the culture of gender is tackled in school, which is deduced through the recognition and analysis of discourses, subjects and mechanisms of discussion used by these teachers. Moreover, in our case, this technique is particularly appropriate in exploring how teachers construct their professional identity in relation to equality, and in understanding the actions and practices that participants perform as a result of assuming a gender perspective.

\section{Aims of the Research}

In a more detailed way we drew up the following study objectives:

1. To analyze how expert teachers in co-education construct meanings about gender (in) equality.

2. To identify "discursive strategies" used by teachers to construct shared meanings about equality between men and women. 
3. To study what "invocations" are used by teachers to validate their points of view about equality between men and women.

\section{Participants}

Thirty-one female and four male Secondary Education teachers were selected for the study using the following accumulative inclusion criteria: 1) a secondary education teacher in Andalusia; 2) named as responsible for the Equality Plan implementation in their school and, 3) had active experience, interest and training in the area of co-education and gender equality. Of the 35 participants, 19 were from Seville and 16 from Granada. Further, 30 of the total were aged between 40 and 60 years, and 5 over 60 years. As for the background on co-education programs and gender equality curriculum, 5 participants had more than 20 years working in the field, 19 participants had between 10 and 20 years of experience, and five had less than 10 years. In fact, 30 of the total were involved in several projects.

In this paper we selected the second group for discussion, from a total of five, because some of its members had longer experience in co-education and they had developed more intense and rich discussions about gender culture in school (State, 1995). The characteristics of the participants are presented in table 1.

[Table 1 near here]

\section{Procedure}

Five group discussions were set up, each consisting of between 5 and 8 teachers, with each meeting lasting approximately 90 minutes. The group discussions were held in the Education and Psychology Faculties of the Universities of Granada 
and Seville during June and September, 2009. At the start of each session, the question guide was handed over to the teachers and they were told how long the discussion would last ${ }^{2}$.

The discussions were stimulated by the following open-ended questions: 1) notions and objectives of co-education, 2) ideas and practices in the area of gender culture in schools, 3) the impact of equality plans in education, 4) positions and attitudes towards the construction of gender in the school community, 5) repercussions of these positions and attitudes. But, as it is common in group discussions, participants can determine their own topics of debates, and when and how they want to talk about them. In each group there were two researchers and the authors of this paper (one woman and one man) who assumed the roles of moderator or observer participant. Participants were given guarantees that all information would be treated in an anonymous way for the purposes of the study, and they were asked to give their consent for audio-visual recording.

\section{Data analysis}

Our approach to discourse analysis has allowed us to identify the contradictions, ambivalences and conflicts in the teachers' discourses. This approach provides methodological procedures for the analysis of discursive interaction, providing keys for the identification and processing of the units of analysis. The data analysis procedure involves the recognition and coding of discourse on the basis of two units of analysis of a different but complementary nature. They are: 1) "discursive episodes" which integrate sets of utterances which share the same discursive purpose and which make it possible to monitor and characterize the main discursive conflicts in debates; and, 2) "utterances", which constitute the real unit of 
communication (Bakhtin 1986) and in turn its most basic expression with narrative meaning and properties. The categories which have emerged from this process of analysis and which are discussed here are presented in tables 2 and 3.

[Table 2 near here]

[Table 3 near here]

\section{Results and discussion}

During the teachers' interactions, 14 conflicts were registered. More than half of them were contextual; in other words, they revolved around the difficulties faced by teachers when it came to implementing the Equality Plan in their schools due to coinciding or contrasting opinions of the teaching staff in favor of, or against, the Plan. Of the 1983 transcribed utterances, 572 were related to these conflicts, representing $30 \%$ of participants' discourses. Most of these were concerned with two subjects: the climate or state of opinion of the educational community concerning gender equality (36\%), and the interpretation and application of the regulation in the school context (36\%). For this paper, we have selected a conflict that is representative of the dynamics which the application of the Plan generates in schools and of the reactions among the teaching staff produced by the introduction of feminist thinking in educational practice. "Identifying and recognizing inequality" is a contextual conflict which expresses the lack of consciousness or awareness of the teaching staff about the existence of gender inequality and the need to intervene to correct and reduce specific practices and situations of discrimination. On the "socio-cultural level", this conflict questions the need for the Equality Plan and the work which is being conducted by the teachers implementing it at school, and it is represented by the voice "inequality does not exist" (see below). On the "interactive level", this voice 
also means a conflict which reveals the devaluation of the work of teachers responsible for applying the Plan, mainly feminist women with a long professional trajectory in this field, forcing them to defend their activity and justify the need for it. This social voice "inequality does not exist", which penetrates schools through the discourse of one teacher, provides the opportunity to deploy a whole set of strategies and resources to construct shared meanings about gender equality at school. The analysis of the discursive episode or conflict has been summarized in table 4 .

[Table 4 near here]

We will show three episodes from this conflict, which arises from the different points of view about whether inequality between men and women does or does not exist. The analysis of the episodes has been summarized in table 5 .

Extract $1^{1}$

1805 María: I think that people have the idea that there isn't so much inequality today, and that 1806 women are progressing a lot, and they are occupying a lot of areas ... so, there isn't 1807 inequality, which isn't perceived, you understand? That inequality isn't perceived or, 1808 at least, a lot of teachers have that idea.

1809 Pedro: In fact, there's no such inequality at my school

1810 (The rest of the group murmur)

1811 Susana: Let's see if we can work it out, because I'm not sure about that

1812 Julia: I can show you the school lists if you want

1813 Pedro: Well, it's possible there is inequality at high level principals, but at the present time, 1814 even in numbers, there are many more female teachers

1815 Julia: Yes, but a male teacher is more respected by students than a female teacher.

1816 María: Yes, they are the top management, there for the professional careers and so on.

1817 However, our pupils address us as if we were their mums because we are women and 1818 if a male teacher will arrives and shouts, then everybody respects him.

In extract 1, we can say that the topic is related to the question: "Is or isn't there inequality between men and women at the present time?" The event which sparks off the conflict is the first María's intervention which, with a certain amount of irony, denounces the lack of awareness or short-sightedness of the teaching staff as a "sensitizing" discursive strategy invoking "the cultural experience" of the group. Pedro states that in his school there is no inequality and, using his own experience to 
argue against the existence of inequality, unleashes the conflict, seeming to question the need for the Equality Plan. As a response to that argument, Julia uses the "visualization" of inequality by referring to statistical data on the number of men and women who are school principals as evidence of doing gender. The argument used by Julia to construct and validate shared meanings about gender inequality, is a good example of how gender is done in educational settings in terms of teachers' discursive and semiotic resources. The naturalization or normalization of inequality means gender construction arises in discursive actions, let's say here and now, it means to do gender.

But with that intervention this teacher not only visualizes inequality, she also resorts to the invocation of "institutional authority" to validate her points of view. It is interesting to highlight how, in this case, the teacher takes a line of argument based on a more formal institutional authority (data coming from the Woman Institute research papers) to reinforce her point of view, using a more persuasive argument (Bruner 2006). Invoking the "institutional authority" also seems to be accepted by Pedro, who asserts that gender equality existed, as he uses this same type of reasoning to counter the arguments of his most direct interlocutor, as we can see in lines 1813 and 1814 in which he refers to statistics of the number of teachers depending on sex quote him.

However, the resources used by some participants to persuade others of their point of view do not just cover the sphere of documents and official texts as we have seen in the utterances of Julia ("I can show you the school lists if you want") and Pedro ("Well, it's possible there is inequality at high level principals, but at the present time, even in numbers, there are many more female teachers") in extract 1. Once they have been presented, the actual shared experience as members of the same community, of teachers, may acquire great persuasive power. In this sense, Julia 
("Yes, but a male teacher is more respected by students than a female teacher") and María ("Yes, they are the top management, there for the professional careers and so on. However, our pupils address us as if we were their mums because we are women and if a male teacher will arrives and shouts, then everybody respects him") use a discursive strategy of "visualization", to make evident the different ways that male and female teachers are treated in their daily interactions with students, invoking the "cultural experience" of the group.

This combined use of different types of invocations, far from being inconvenient or insufficient, could be understood in positive terms as an extension of the sources of validation in the conversation, which undoubtedly increases the persuasive power of the line of argument participants follow. This could be extended to the discursive strategies used; to illustrate it we shall present a second episode of this conflict. The "subject" of this second episode relates to "the difficulty of working in co-education due to the naturalization of inequality".

\section{Extract 2}

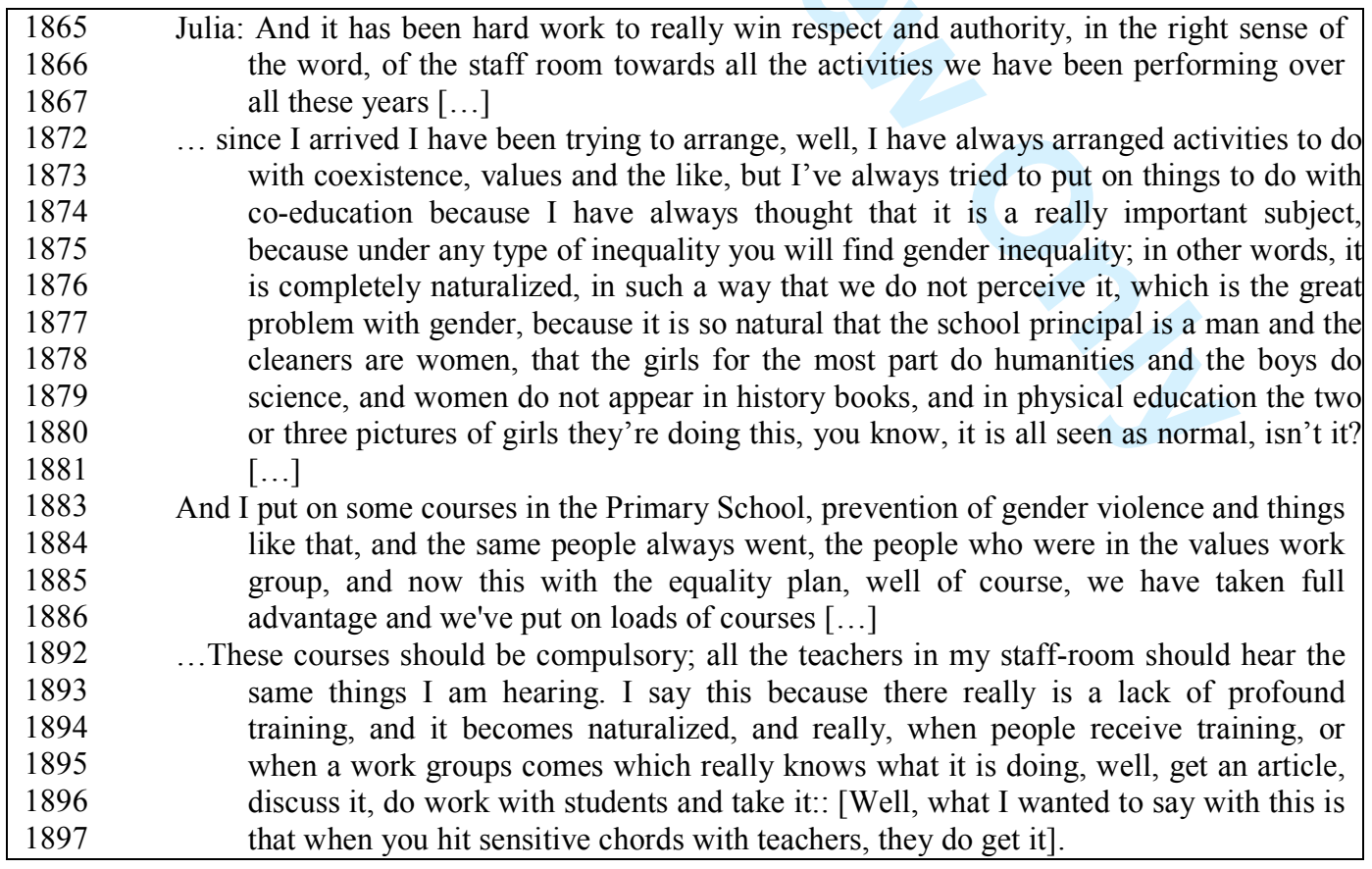


In the analysis of the utterances in this episode we could say that Julia uses different types of strategies to do gender. At different moments of her intervention she uses strategies of "empowerment", in which she includes and even takes part in actions aimed at making gender inequality evident and towards training in coeducation. For example, when she says "And it has been hard work to really win respect and authority, in the right sense of the word, of the staff room towards all the activities we have been performing over all these years" (but also in lines 1872-1874 and 1883-1886). To validate these interventions she resorts to invocations based on her "personal experience" as a trainer and advocate of training courses in gender equality.

This strategy is used together with a strategy of "visualization" of inequalities of gender in different areas of daily and academic life, as from lines 1874 to 1880 . In this case, she resorts both to invocations to "institutional authority" ("I have always thought that it is a really important subject, because under any type of inequality you will find gender inequality; in other words, it is completely naturalized, in such a way that we do not perceive it, which is the great problem with gender") and to "cultural experience to validate her point of view - ("because it is so natural that the school principal is a man and the cleaners are women, that the girls for the most part do humanities and the boys do science, and women do not appear in history books, and in physical education the two or three pictures of girls they're doing this ").

Finally, and complementarily, in this second episode, she uses the strategy of "sensitizing" as a discursive devise for constructing shared and negotiated knowledge about gender. Thus, when she says "These courses should be compulsory; all the teachers in my staff-room should hear the same things I am hearing. I say this because there really is a lack of profound training, and it becomes naturalized, and 
really, when people receive training, or when a work groups comes which really

knows what it is doing, well, get an article, discuss it, do work with students and take

$i t$ ", she refers to the importance of everyone working towards equality, for which she

draws on "teaching profession knowledge" as a criteria for validation.

To finish the analysis of this conflict we now present a third episode. The "subject" of this third episode revolves around "the difficulty that men in particular have in perceiving the inequality that affects women at a time when significant progress has been made in gender equality".

\section{Extract 3}

\begin{tabular}{|ll}
\hline 1914 & Julia: This morning, for example, I was talking to an inspector and telling him that there were \\
1915 & only a few women at the inspection. "Damn it!, I don't know why you complain if you \\
1916 & have advanced a lot in recent years! Besides, if you want to win a prize in the lottery, \\
1917 & you will have to buy a lottery ticket, come on, and become an inspector yourself!" Wait \\
1918 & a minute, we aren't talking about that, it's question of seeing why women can't get \\
1919 & certain responsibilities, do you understand? When you have to debate about equality, \\
1920 & sometimes it's very difficult to make working groups with people who can move and \\
1921 & provoke other people and if you get this, people will join, do you know what I mean? \\
1922 & There are two kinds of positions about this subject. On one hand, those people for \\
1923 & whom co-education produces repulsion because it's like the (military) wing of feminism \\
1924 & in education and feminism has created a lot of repulsion. The Franco system said that \\
1925 & feminists were crazy women. On the other hand, it (feminism) has created very \\
1926 & forthright people who have begun to work about these subjects and, they are working \\
1927 & overtime, do you know? In other words, there are two attitudes towards this subject. But \\
1928 & the most important thing, as I say, is for people to join the cause. \\
1930 & Amanda: And I just wanted to say, that up to that point, we, the teachers have a bandage \\
1931 & covering our eyes on this subject, and when we made the diagnosis we saw that the boys \\
1932 & were the ones occupying the patio, with the girls all standing round the side, and in the \\
1933 & classes the girls sat together and the boys somewhere else, and the boys were more \\
1934 & participative, they were the ones who interrupted the class (...)
\end{tabular}

Again Julia argues by trying to construct a shared knowledge about gender that would enable teachers to do gender in education institutions. She starts by complaining about the lack of awareness about inequality. In our study it seems particularly noteworthy that one of the ways in which the strategy of "visualization" is used is by complaining about teachers' lack of awareness of gender equality, as when Julia says "This morning, for example, I was talking to an inspector and telling him that there were only a few women at the inspection. 'Damn it, I don't know why you 
complain if you have advanced a lot in recent years! Besides, if you want to win a prize in the lottery, you will have to buy a lottery ticket, come on, and become an inspector yourself!' Wait a minute, we aren't talking about that, it's question of seeing why women can't get certain responsibilities, do you understand?" This "Gender Blindness" is well documented as a crucial factor for inhibiting the promotion of changes towards equality between men and women (Carrera, Depalma and Lameiras, 2011; Santamaría et al. 2013; Verdonk et al. 2009). This strategy, gender blindness, is one of the most widely used by groups who undertake active gender policies, presenting different points of view or "voices", which come into conflict on subjects of gender equality. These are voices which are embodied in specific discourses (of a colleague, the principal, etc.) but carry different ideological positions that come into conflict in questions of equality. These discordant voices tend to appear through the use of irony as a rhetorical device and a direct style, as mechanisms that alter the normative use of language and contribute to attracting attention, surprising with their originality and persuasiveness, and allowing more effective communication. Maybe because of that, both in this case and in the first episode (when María says: "I think that people have the idea that there isn't so much inequality today, and that women are progressing a lot, and they are occupying a lot of areas ... so, there isn't inequality, which isn't perceived, you understand?') this strategy was formulated using a broad set of prosodic resources (intonation, accentuation, rhythm, speech velocity, exclamations, raised tone of voice, etc.) which obviously has a communicative function. Finally, this discursive strategy rested, as was to be expected, on the use of "personal experience" as a source of validation of the argumentation presented. 
In this episode, Julia uses strategies of "sensitizing" to discuss how it is possible, if one works with active, provocative people, to make sure that "people will join" (line 1921) and that "people will join the cause“" (line 1930), on the basis of the "cultural experience" of the group. Perhaps she uses "cultural experience" as a way to validate her argument because most of the participants have a great deal of experience in co-education work groups, and in projects of educational innovation in gender, etc. Through the use of the "visualization" strategy, this teacher gives her own interpretation of the two points of view, two voices or two ideologies which come into conflict in the recognition or not of the inequality between men and women. In this case, Julia resorts both to invocations to "cultural experience" ("There are two kinds of positions about this subject. On one hand, those people for whom co-education produces repulsion") and to "ideology" ("The Franco system said that feminists were crazy women") to validate her standpoint. To defend the existence of the former she resorts, as a source of validation, to the dominant ideology of a specific historical period in Spain, under Franco's regime, whose influence can still be felt today.

This intervention of Julia forces Amanda to assume this position and strengthens Julia's point of view in the group, which leads to the conflict being resolved by the group as they adopt this line of argument (being an extremist on issues of co-education or non-sexist language produces rejection in many people) and thereby recognizes Julie's authority on the subject. Through the use of the "sensitizing" strategy, as when Amanda says "And I just wanted to say, that up to that point, we, the teachers have a bandage covering our eyes on this subject", Amanda shows that she shares Julia's point of view and she resorts, as a source of validation, to "cultural experience". Further, through the use of "visualization", she gives more examples of her "personal experience" as a source of validation of the argumentation 
presented by Julia and herself, as when Amada says "boys were the ones occupying the patio, with the girls all standing round the side, and in the classes the girls sat together and the boys somewhere else, and the boys were more participative, they were the ones who interrupted the class".

The following table is an outline of the different extracts analyzed.

[Table 5 near here]

A microanalysis of teachers' discourses has allowed us to study how a shared knowledge about gender equality and the role of the school and their work coalesces around gender. The analysis of the teachers' discourses in the resolution of conflicts which arose in the understanding and application of the Equality Plan has provided us with an opportunity to study how they work out these new codes and regulations for educational practice and integrate a gender perspective. It has helped us understand the social process through which teacher experts in co-education construct gender culture in the school settings, providing different levels of analysis of the interactions and conflicts that the teachers experience while applying the Equality Plan. At the same time, discourse analysis has given us conceptual tools to study the process of the construction of new, shared meanings on gender equality in the school settings, and this in turn has allowed us to study how the socio-cultural level is created and recreated dynamically in interactions. We have used "invocations", which have already proven to be a valuable resource in the shared construction of meaning in school contexts, to find out how knowledge about gender equality is constructed as a result of the implementation of a new educational policy on this subject. We also found that teachers use a variety of discursive strategies to do gender, with "visualization" and "sensitizing" being very present when coping with the resolution of conflicts in the school settings. 


\section{Conclusions}

The main aim of this article was to examine how Andalusian teachers who are experts in co-education discuss gender (in) equality and in doing so construct shared meanings about gender equality and how these meanings can influence their practices. Our main argument is that the Plan for Equal Opportunities between women and men in education offered an opportunity to change the culture of gender in school settings. From a research standpoint, it gave us the chance to observe this process of change with a micro-analytical lens in the early stages of its implementation. In formal terms, the Plan meant that schools had to assume the social role of correcting gender imbalances and inequalities by adopting the gender perspective as the backbone of educational practice. Its implementation was responsible for introducing social debate about equality between men and women into the school and into the discourses and practices of the teaching staff as a central issue.

Analysis of discussions of the Equality Plan revealed the strong presence of social voices skeptical of equality in the school, such as inequality doesn't exist, women are making too much progress, etc., highlighting the reality of the social context and suggesting the need for further action to highlight gender inequality. This indicates that gender is done at school settings through multiple social voices embodied in the discourses and interactions which take place in the school context. The policies and plans for promoting gender equality in education help to counteract these voices' socio-educational influence, by introducing and giving value to other voices and discourses coming from feminists in educational practice. In a previous study, Santamaría, et al. (2013) revealed the variety of voices which inhabit the discourses of teachers in relation to the changes in the subject of gender equality at 
school. They saw these voices as a useful analytical tool to lay bare the social, cultural, institutional and historical context in which the conversation takes place and to reveal the position taken by teachers in these processes of change. To do this, the most argumentative and persuasive discourse is used by female teachers with an awareness strategy aimed at countering the influence of these voices in the educational context, accompanying this with a rich variety of invocations to legitimize and validate their points of view, with particular emphasis on "cultural experience" and "ideology", as we saw here. The women's movement seeks to promote gender consciousness through collective actions to improve women's position in society (Liss, et al. 2001; Reid and Purcell 2004). A substantial body of research has focused on gender training and awareness for teachers as a crucial factor for promoting favorable changes towards equality between men and women (Carrera, Depalma and Lameiras 2011; Verdonk et al. 2009). Rebollo, et al. (2011) found a wide repertoire of strategies for doing gender at school settings, with the use of argumentation with forms of theoretical and practical reasoning being more widespread when they want "people to join the cause".

In this paper we have developed a methodological approach to analyze discursive practices that create shared meanings in school settings and produce changes in school culture about gender equality. This approach has helped to study how expert teachers in co-education do gender through their discourse and interactions, but it has also helped to identify key features of social contexts that are either obstacles or advantages for social changes related to the gender system. The conceptual categories used for the analysis of teachers' discourse reveal useful tools for a combined analysis of the socio-cultural and interactive levels of the social system of gender through the actions of the teachers. In parallel, we would like to 
point out that this approach has also been valuable for revealing the ways in which responsive teachers for the implementation of a Plan for Gender Equality act in school settings to construct new values and meanings associated with equality between women and men, identifying how they act and the resources they draw on to do so.

As we have pointed out above, the purpose of the First Strategic Plan was to address and overcome different forms of gender discrimination. More specifically, it was intended to create conditions and structures that promote equal opportunities for women and men in our region. We think that in order to achieve this goal, a necessary condition is the active participation and involvement of all sectors in Andalusian society. Its implementation in wider society will make the plan an appropriate and useful tool to advance towards real and effective equality between women and men.

The important legal advances in our region during the last decades have not yet allowed us to overcome gender inequity. The new legislation and the implementation of the Andalusian Plan for Gender Equality in education alone will not bring the necessary changes. We also need to train professionals capable of developing educational activities in areas such as equal opportunities, gender violence co-education and sexual education. All these activities must involve specific training in gender and co-education. For this reason, we think that there is still much to be done, including: a) to incorporate gender perspectives in all courses and training activities involving professionals working with young people, b) to promote the effective participation of associations (especially women's associations) in the transmission of equitable gender values, as well as in co-education projects in schools (i.e. by participating in school councils), c) to establish general educational strategies for alternative conflict resolution, such as dialogue, conciliation, negotiation or mediation, and d) to promote the balanced participation of women and men in school 
boards and other positions of responsibility, as well as in teaching at all levels. We need, in sum, to train teachers who must be experts not only in the different subjects of the curriculum, but in gender perspectives in their educational practices. The current offers a preliminary approach to the analysis of how these teachers who are experts in co-education might understand and implement the legal principles of gender equity. The road to gender equality will be long and possibly difficult, but definitely exciting.

\section{Notes}

1. The materials analyzed and the results presented in this article come from a larger research project that was funded by a grant from the Andalusian Regional Government (Proyecto de Excelencia “Teón XXI: Creación de recursos digitales para el conocimiento y difusión de la cultura de género en la escuela", P06-HUM-01408), aimed at making a diagnosis of gender culture in secondary schools in Andalusia. Once done, we will discuss the results and point out some preliminary conclusions.

2. For conducting group discussions, we enjoyed the cooperation of advisors from Teacher Centers of Seville and Granada (CEPS) who selected teachers taking into consideration the inclusion criteria. They also provided us with the information to contact them on their centers. We negotiated with teachers and advisors the timetable to collect data. Teachers participated voluntarily and they filled out the authorization requested to participate and to be video registered.

3. To maintain teachers' confidentiality and anonymity, we have changed their names in the transcripts. We also removed some references with which participants could be identified (names of their centres, names of co-workers, projects in which they were involved, etc.). 


\section{References}

Bakhtin, Mihail. 1986. Speech genres and other late essays Austin: University of Texas Press.

Bohnsack, Ralf. 2004. Group discussion and focus group. In Flick, Uwe, von Kardorf, Emst, Steinke, Ines, eds. A Companion to Qualitative Research, 214-221. Sage, London.

Butler, Judith. 1990. Gender Trouble. New York: Routledge.

Butler, Judith. 1993. Bodies that Matter: On the Discursive Limits of "sex". New York: Routledge.

Bruner, Jerome. 2006. In Search of Pedagogy. Selected Works of Jerome Bruner. London, New York: Routle.

Carrera, María, Renée DePalma, and María Lameiras. 2011. Toward a More Comprehensive Understanding of Bullying in School Settings. Educational Psychology Review 23:479-499.

Crawford, Mary. 2006. Transformations. Women, Gender and Psychology. McGrawHill: Boston.

Crawford, Mary, and Roger Chaffin. 1997. The meanings of difference: cognition in social and cultural context. In Gender differences in human cognition, ed. P.J. Caplan, M. et al., 81-130. Oxford: Oxford University Press

Cuenca Gómez, Patricia. 2008. Mujer y constitución: los derechos de la mujer antes y después de la Constitución Española de 1978. Universitas. Revista de Filosofia, Derecho y Política, 8, 73-103. 
Cubero, Rosario, and María José Ignacio. 2011. Accounts in the classroom: Discourse and the co-construction of meaning. Journal of Constructivist Psychology 24:234-267.

Danielsson, Anna T. 2012. Exploring woman university physics students 'doing gender' and 'doing physics'. Gender and Education 24(1):25-39.

Departamento de redacción Civitas. 2011. Constitución Española. Madrid: Civitas.

Garfinkel, Harold. 1967. Studies in Ethnomethodology. Englewood Cliffs, N.J.: Prentice-Hall.

Institute for Women. 2008. Guía de Co-educación. Síntesis sobre la Educación para la Igualdad de Oportunidades entre Mujeres y Hombres. Madrid: Instituto de la Mujer (Ministerio de Igualdad), Gobierno de España.

Junta de Andalucía. 2005. I Plan de Igualdad entre Hombres y Mujeres en Educación. Sevilla: Consejería de Educación, Junta de Andalucía.

Kabeer, Naila. 2005. Gender equality and women's empowerment: A critical analysis of the third millennium development goal. Gender \& Development 13:13-24.

Kitzinger, Celia. 2009. Doing gender: a conversation analytic perspective. Gender \& Society 23:94-98.

Liss, Miriam, Christy O’Connor, Elena Morosky, and Mary Crawford. 2001. What Makes a Feminist? Predictors and Correlates of Feminist Social Identity in College Women. Psychology of Women Quarterly 25:124-133.

Lombardo, Emannuela. 2005. Integrating or setting the agenda? Gender mainstreaming in the European constitution-making process. Social Politics: International Studies in Gender, State and Society 12:412-32. 
Marshall, Judi. 1999. Doing gender in management education. Gender and Education 11(3):251-263.

Martin, Patricia. 2003. "Said and done" versus "saying and doing": Gendering practices, practicing gender at work. Gender \& Society 17:342-366.

Mercer, Neil. 2000. Words and Minds: how we use language to think together. London: Routledge.

Messerschmidt, James. 2009. "Doing Gender": The Impact and Future of a Salient Sociological Concept. Gender \& Society 23:85-88.

Rebollo, Ángeles, Luisa Vega, and Rafael García. 2011. El profesorado en la aplicación de planes de igualdad: conflictos y discursos en el cambio educativo (The teachers in the implementation of equality plans: conflict and discourse in educational change). Revista de Investigación Educativa 29(2):311-323.

Rader, Nicole E. and. Jeralynn S, Cossman, 2011. An Examination of the Gendered Nature of College Men and Women's Fear for Others. Sex Roles 64: 568-581.

Reid, Anne, and Nuala Purcell. 2004. Pathways to Feminist Identification. Sex Roles 50:759-769.

Ridgeway, Cecilia. 2009. Framed Before We Know It: How Gender Shapes Social Relations. Gender \& Society 23:145-160.

Rommetveit, Ragnar. 1979. On the architecture of intersubjectivity. In Studies on language, thought and verbal communication, ed. R. Rommetveit and R. M. Blackar, 147-171. London: Academic Press.

Santamaría, Andrés, Mercedes Cubero, María del Mar Prados, and Manuel Luis de la Mata. 2013. Posiciones y voces ante el cambio coeducativo: La construcción de la 
1

2

3

4

5

6

7

8

9

10

11

12

13

14

15

16

17

18

19

20

21

22

23

24

25

26

27

28

29

30

31

32

33

34

35

36

37

38

39

40

41

42

43

44

45

46

47

48

49

50

51

52

53

54

55

56

57

58

59

60

identidad del profesorado en la aplicación de planes de igualdad (Positions and voices in the coeducational change: identity construction of teachers in implementing equality plans). Profesorado: Revista de curriculum y formación del profesorado 17:27-41.

Verdonk, Petra, Yvonne Benschop, Hanneke de Haes, and Toine Lagro-Janssen. 2009. From gender bias to gender awareness in medical education. Advances in Health Sciences Education 14(1):135-152.

Wertsch, James. 1991. Voices of the mind. Londres: Harvester Wheatsheaf.

West, Candace, and Don Zimmerman. 1987. Doing Gender. Gender \& Society 1:125151.

West, Candace, and Don Zimmerman. 2009. Accounting for Doing Gender. Gender \& Society 23:112-122. 
Tables

Table 1. Characteristics of the group discussions selected.

\begin{tabular}{cllc}
\hline Variables & \multicolumn{1}{c}{ Categories } & Frecuency & Percentage \\
\hline Cities & Seville & 6 & \\
\hline \multirow{2}{*}{ Sex } & Female & 5 & $83 \%$ \\
\cline { 2 - 4 } & Male & 1 & $17 \%$ \\
\hline \multirow{2}{*}{ Ages } & From 40 up to 60 years & 5 & $83 \%$ \\
\cline { 2 - 4 } & Over 60 years & 1 & $17 \%$ \\
\hline Coeducation experiences & Less than 10 years & 1 & $10 \%$ \\
\cline { 2 - 4 } & Between 10 and 20 years & 3 & $50 \%$ \\
\cline { 2 - 4 } & More than 20 years & 2 & $40 \%$ \\
\hline $\begin{array}{c}\text { Participation in coeducation } \\
\text { projects }\end{array}$ & Yes & 4 & $67 \%$ \\
\cline { 2 - 4 } & No & 2 & $33 \%$ \\
\hline \multirow{2}{*}{\begin{tabular}{c} 
proje \\
\cline { 2 - 4 }
\end{tabular}} & & & \\
\hline
\end{tabular}

Table 2. Type of Conflict.

\begin{tabular}{|lll}
\hline \multicolumn{1}{c}{$\begin{array}{c}\text { Unit of } \\
\text { analysis }\end{array}$} & \multicolumn{1}{c}{ Categories } & \multicolumn{1}{c}{ Subcategories } \\
\hline $\begin{array}{l}\text { Discursive } \\
\text { episodes o } \\
\text { conflict }\end{array}$ & Conflict type & Contextual or Strategic \\
\cline { 2 - 3 } & Conflict plane & $\begin{array}{l}\text { Socio-cultural and } \\
\text { Interactive }\end{array}$ \\
\cline { 2 - 3 } & Conflict topic & $\begin{array}{l}\text { Regulation, Curriculum, } \\
\text { Language or Climate }\end{array}$ \\
\hline
\end{tabular}

Table 3. Type of utterances.

\begin{tabular}{|c|c|c|c|}
\hline $\begin{array}{l}\text { Unit of } \\
\text { analysis }\end{array}$ & Categories & Subcategories & Definitions \\
\hline \multirow[t]{5}{*}{ The utterances } & \multirow[t]{3}{*}{$\begin{array}{l}\text { Discursive } \\
\text { strategies }\end{array}$} & Visualization & $\begin{array}{l}\text { Actions oriented towards reporting situations } \\
\text { and practices which condition the } \\
\text { development of people depending on their } \\
\text { gender in school contexts. Particular emphasis } \\
\text { is laid on the naturalization or normalization } \\
\text { of inequality }\end{array}$ \\
\hline & & Sensitizing & $\begin{array}{l}\text { Actions aimed at making teachers aware of } \\
\text { equality. These actions are based on the } \\
\text { argumentation and persuasion to create a } \\
\text { gender shared consciousness amongst } \\
\text { teachers. }\end{array}$ \\
\hline & & Empowerment & $\begin{array}{l}\text { Actions aimed at increasing capacity for } \\
\text { having an influence on and taking part in } \\
\text { decision-making about school culture and life. } \\
\text { Includes actions aimed at empowering the } \\
\text { collective }\end{array}$ \\
\hline & \multirow[t]{2}{*}{ Invocations } & $\begin{array}{l}\text { Personal } \\
\text { experience }\end{array}$ & $\begin{array}{l}\text { Utterances based on knowledge from } \\
\text { speakers'everyday lives and their personal } \\
\text { experiences. }\end{array}$ \\
\hline & & $\begin{array}{l}\text { Cultural } \\
\text { experience }\end{array}$ & $\begin{array}{l}\text { Utterances based on experiences, knowledge } \\
\text { and events which are shared as people }\end{array}$ \\
\hline
\end{tabular}


Table 4. Some data of the conflict analyzed.

\begin{tabular}{clll}
\hline \multicolumn{1}{c}{ Conflict } & \multicolumn{1}{c}{ Variables } & \multicolumn{1}{c}{ Categories } & \multicolumn{1}{c}{ Descriptions } \\
\hline $\begin{array}{l}\text { Identifying } \\
\text { and } \\
\text { recognizing } \\
\text { of inequality }\end{array}$ & $\begin{array}{l}\text { 1.1 Conflict } \\
\text { type }\end{array}$ & Contextual & $\begin{array}{l}\text { The lack of consciousness or awareness of the } \\
\text { teaching staff about the existence of gender } \\
\text { inequality and the need to intervene to correct and } \\
\text { reduce specific practices and situations of } \\
\text { discrimination. }\end{array}$ \\
\cline { 2 - 4 } & $\begin{array}{l}\text { 1.2. Conflict } \\
\text { plane }\end{array}$ & $\begin{array}{l}\text { Socio-cultural } \\
\text { Level }\end{array}$ & $\begin{array}{l}\text { The need for the Equality Plan and the work } \\
\text { which is being conducted by the teachers } \\
\text { implementing it at school, }\end{array}$ \\
\cline { 2 - 4 } & $\begin{array}{l}\text { Interactive } \\
\text { Level }\end{array}$ & $\begin{array}{l}\text { The devaluation of the work of the responsible } \\
\text { teachers for applying the plan by some colleagues } \\
\text { of work, which force them to defend their activity } \\
\text { and justify the need for it. }\end{array}$ \\
\hline $\begin{array}{lll}\text { 1.3. Conflict } \\
\text { topic }\end{array}$ & Climate & $\begin{array}{l}\text { The state of opinion of the educational } \\
\text { community concerning gender equality. }\end{array}$ \\
\hline
\end{tabular}

Table 5. Some issues of the utterances analyzed.

\begin{tabular}{|c|c|c|c|c|}
\hline Extracts & Topic & & Utterances & \\
\hline & & Discoursive strategies & Invocations & Lines \\
\hline \multirow[t]{4}{*}{ Extract 1} & \multirow{4}{*}{$\begin{array}{l}\text { "Is or isn't there } \\
\text { inequality between } \\
\text { men and women at } \\
\text { the present time?" }\end{array}$} & 2.1.2. Sensitizing & $\begin{array}{l}\text { 2.2.2. Cultural } \\
\text { experience }\end{array}$ & $\begin{array}{l}\text { María at } 1, \\
1805 \text { to } 1807\end{array}$ \\
\hline & & 2.1.1. Visualization & $\begin{array}{l}\text { 2.2.4. Institutional } \\
\text { authority }\end{array}$ & Julia at 1,1812 \\
\hline & & 2.1.1. Visualization & $\begin{array}{l}\text { 2.2. 2. Cultural } \\
\text { experience }\end{array}$ & $\begin{array}{l}\text { Julia at } 1, \\
1815\end{array}$ \\
\hline & & 2.1.1. Visualization & $\begin{array}{l}\text { 2.2.2. Cultural } \\
\text { experience }\end{array}$ & $\begin{array}{l}\text { María at } 1, \\
1816 \text { to } 1818\end{array}$ \\
\hline \multirow[t]{4}{*}{ Extract 2} & \multirow{4}{*}{$\begin{array}{l}\text { "The difficulty of } \\
\text { working in co- } \\
\text { education due to } \\
\text { the naturalization } \\
\text { of inequality" }\end{array}$} & 2.1.3. Empowerment & $\begin{array}{l}\text { 2.2.1. Personal } \\
\text { experience }\end{array}$ & $\begin{array}{l}\text { Julia, at } 2, \\
1865 \text { to } 1867, \\
1872 \text { to } 1873, \\
1883 \text { to } 1886\end{array}$ \\
\hline & & 2.1.1. Visualization & $\begin{array}{l}\text { 2.2.4. Institutional } \\
\text { authority }\end{array}$ & $\begin{array}{l}\text { Julia, at } 2, \\
1873 \text { to } 1876\end{array}$ \\
\hline & & & $\begin{array}{l}\text { 2.2.2. Cultural } \\
\text { experience }\end{array}$ & $\begin{array}{l}\text { Julia, at } 2, \\
1877 \text { to } 1880\end{array}$ \\
\hline & & 2.1.2. Sensitizing & $\begin{array}{l}\text { 2.2.3. Teaching } \\
\text { profession } \\
\text { knowledge }\end{array}$ & $\begin{array}{l}\text { María, at } 2, \\
1892 \text { to } 1897\end{array}$ \\
\hline Extract 3 & $\begin{array}{l}\text { "The difficulty that } \\
\text { particularly men }\end{array}$ & 2.1.1. Visualization & $\begin{array}{l}\text { 2.2.1. Personal } \\
\text { experience }\end{array}$ & $\begin{array}{l}\text { Julia at } 3, \\
1914 \text { to } 1919\end{array}$ \\
\hline
\end{tabular}




\begin{tabular}{|c|c|c|c|}
\hline \multirow[t]{6}{*}{$\begin{array}{l}\text { have of perceiving } \\
\text { the inequality that } \\
\text { affects women" }\end{array}$} & 2.1.2. Sensitizing & $\begin{array}{l}\text { 2.2.2. Cultural } \\
\text { experience }\end{array}$ & $\begin{array}{l}\text { Julia at } 3, \\
1919 \text { to } 1922, \\
1928 \text { to } 1930\end{array}$ \\
\hline & 2.1.1. Visualization & $\begin{array}{l}\text { 2.2.2. Cultural } \\
\text { experience }\end{array}$ & $\begin{array}{l}\text { Julia at } 3, \\
1922 \text { to } 1925\end{array}$ \\
\hline & & 2.2.5. Ideology & $\begin{array}{l}\text { Julia at 3, } \\
1925\end{array}$ \\
\hline & & $\begin{array}{l}\text { 2.2.2. Cultural } \\
\text { experience }\end{array}$ & $\begin{array}{l}\text { Julia at } 3, \\
1926 \text { to } 1927\end{array}$ \\
\hline & 2.1.2. Sensitizing & $\begin{array}{l}\text { 2.2.2. Cultural } \\
\text { experience }\end{array}$ & $\begin{array}{l}\text { Amanda, at 3, } \\
1930 \text { to } 1931\end{array}$ \\
\hline & 2.1.1. Visualization & $\begin{array}{l}\text { 2.2.1. Personal } \\
\text { experience }\end{array}$ & $\begin{array}{l}\text { Amanda, at 3, } \\
1931 \text { to } 1934\end{array}$ \\
\hline
\end{tabular}

